\section{Performance Evaluation of Bulk Liquid Membrane Technique on $p$-Nitrophenol Removal from Aqueous Solution}

\author{
K. Pourkhanali, M. Saleh, and G. Khayati* \\ Department of Chemical Engineering, Faculty of Eng., \\ University of Guilan, Rasht, P. O. Box 41635-3756, Iran
}

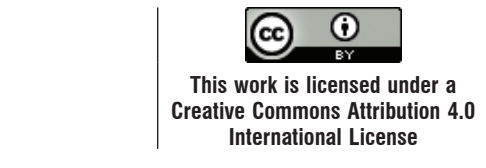

doi: 10.15255/CABEQ.2016.1033

Original scientific paper Received: November 8, 2016 Accepted: February 10, 2018

The transport of $p$-nitrophenol (PNP) through a bulk liquid membrane (BLM) was investigated to evaluate the effect of different experimental conditions on PNP partitioning behavior. The influence of solvent type, different salts in feed phase, the feed phase $\mathrm{pH}$ and PNP concentration in feed phase on transport efficiency of PNP through the BLM were studied. The results indicated that the highest removal efficiency of PNP was observed for $80 \%$ xylene $+20 \%$ toluene as liquid membrane, $\mathrm{Na}_{2} \mathrm{SO}_{4}$ as salt in feed phase, in the acidic feed phase and in $150 \mathrm{~min}$. The effect of initial concentration of PNP on the efficiency of the separation PNP showed that the increase in initial concentration up to $350 \mathrm{ppm}$ had positive effect, and more than $350 \mathrm{ppm}$ had negative effect on the PNP removal behavior. Also, pertraction in BLM systems were described by a kinetic model of two consecutive irreversible first order chemical reactions.

Keywords:

p-nitrophenol removal, bulk liquid membrane, pertraction, separation

\section{Introduction}

Phenolic compounds, especially those with $\mathrm{Ni}$ tro groups, are toxic compounds that cause damage to human beings and other terrestrial and aquatic creatures. $p$-Nitrophenol (PNP), an important member of nitrophenolic compounds, is generally considered one of the most harmful organic pollutants even at low concentrations, for example, prolonged exposure to $p$-nitrophenol can cause cyanosis, anemia, liver and kidney disease, abdominal pain and vomiting, urinary tract infections, inflammation of the respiratory system, allergic reaction of skin and eye irritations, as well as blood disorder, methemoglobin formation which is responsible for confusion and unconsciousness. This is why the United States Environmental Protection Agency (US EPA) included PNP on the 126 proprietary pollutants list ${ }^{1-4}$. This compound can be formed as a result of the reaction of phenolic compounds in the atmosphere in aqueous or gaseous phase. Therefore, to avoid contact with PNP and subsequent damage, wastewater containing PNP must be severely treated before being discharged to the natural water body ${ }^{1,5}$.

PNP is a manufactured chemical that does not occur naturally in the environment. This compound is frequently encountered in residual wastewaters from industries, such as explosives manufacture, pharmaceuticals, wood preservatives, pesticides

"Corresponding author. Tel.: +98 9111329514; E-mail address:

khayati@guilan.ac.ir, khayatiir@googlemail.com used in agriculture, fungicides, pigments, coal conversion, rubber industry, olive presses, and more frequently in oil refining. It is widely used to darken leather. It can also be found in human and animal waste, and in the decomposition of organic mat$\operatorname{ter}^{1,3-5}$.

There are many investigations and several treatment methods to remove nitrophenols such as: adsorption $^{2-4}$, microbiological degradation or biological treatment $t^{6,7}$, chemical oxidation ${ }^{8}$, electrochemical treatment ${ }^{9}$, reverse osmosis ${ }^{10}$, photocatalytic ${ }^{11}$ and sonocatalytic ${ }^{12}$ degradation and membrane separation ${ }^{1,13}$. The disadvantage of adsorption is that it costly because activated carbon is expensive and difficult to regenerate due to chemisorption of PNP. Chemical oxidation requires a large amount of oxidizing agent under severe operating conditions and with the risk of incomplete oxidation, resulting in a more toxic product ${ }^{1,14}$. Also, biological treatment is unsuitable for wastewater with high phenol compound concentrations, such as petrochemical, refinery and pharmaceutical operations ${ }^{14}$, because the complexity of some organic substrates in these wastewaters reduces their biodegradability, and of course, some of them are hardly degraded ${ }^{15}$. In comparison to other treatment methods, liquid membrane has shown good potential for the removal of PNP from wastewater ${ }^{1,13-14,17,25}$. This technique is simple, easy to apply, low on energy consumption, inexpensive, and with high transport efficien$c^{1,16}$. This technique has been effectively used for 
the transport or separation of amines, phenols, amino acids, metallic ions, and pharmaceuticals ${ }^{17}$.

Very little research has been done on PNP removal using the liquid membrane technique. Szczepański and Diaconu ${ }^{17}$ used organic solvents (benzene, toluene and $p$-xylene) as liquid membrane. They demonstrated that the influence of the feed phase concentration (PNP) on pertraction efficiency is much higher than the stripping phase concentration $(\mathrm{NaOH})$ in the examined range of concentration. Also, Diaconu et al. ${ }^{25}$ used a chlorinated solvent $\left(\mathrm{CHCl}_{3}, \mathrm{CH}_{2} \mathrm{Cl}_{2}\right.$ and $\left.\mathrm{CCl}_{4}\right)$ as liquid membrane and $\mathrm{NaOH}$ solution as receiving phase of PNP from aqueous medium through the technique of bulk liquid membrane. They indicated that the solvents used as membrane in the receiving phase of the system varied in this order: $\mathrm{CHCl}_{3}>\mathrm{CH}_{2} \mathrm{Cl}_{2}>\mathrm{CCl}_{4}$.

In the present work, the bulk liquid membrane technique was used to study its ability to remove PNP from aqueous solution. For this purpose, a series of experimental tests was done to investigate the kinetics of PNP pertraction as dependent on the experimental conditions. The influence of initial PNP concentration, $\mathrm{pH}$, different salts, type of organic solvent (benzene, toluene, xylene, n-hexane, olive oil, canola oil and corn oil) as liquid membrane and their volume ratio were investigated. The most interesting features of this study are the choice of mixed solvent and comparison of oils with organic solvents as liquid membrane on PNP removal from aqueous solution using the liquid membrane technique.

\section{Materials and methods}

\section{Materials}

All the reagents used were of analytically grade and without further purification. $p$-Nitrophenol, different salts $\mathrm{NaCl}, \mathrm{NH}_{4} \mathrm{Cl}, \mathrm{KCl}, \mathrm{NH}_{4} \mathrm{NO}_{3}, \mathrm{Na}_{2} \mathrm{SO}_{4}$ and $\left(\mathrm{NH}_{4}\right)_{2} \mathrm{SO}_{4}$ were used in feed phase, $\mathrm{H}_{2} \mathrm{SO}_{4}$ was used for $\mathrm{pH}$ adjustment. All these reagents were purchased from Merck Company (Germany). The aqueous solutions were prepared using Deionized water.

Toluene, xylene, benzene and n-hexane were purchased from Merck Company (Germany). Canola oil, corn oil, and olive oil were purchased from Glucosan Company. All these materials were used as organic solvents in the bulk liquid membrane. Also, deionized water was used as acceptor phase.

\section{Methods}

The experiments were carried out in a glass cell at a constant temperature $297 \mathrm{~K}$ (similar to that of Irdemez et al. ${ }^{18}$, where the temperature of the apparatus was controlled by an external jacket in which

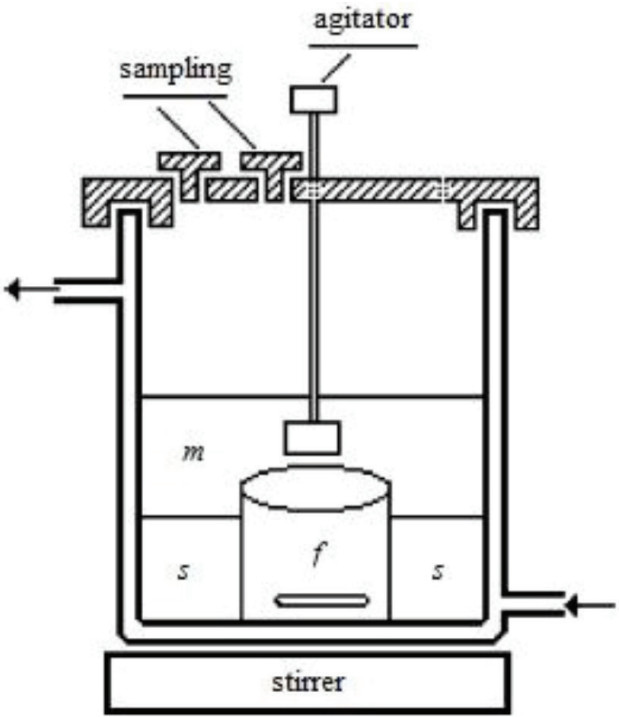

Fig. 1 - Apparatus used for transport of PNP through liquid membranes, (f) feed phase; (m) organic membrane; (s) stripping phase

water was circulated (Fig. 1). The three phases, the feed (or donor) $(f)$, the membrane $(m)$, and the stripping (or acceptor) $(s)$ phases were applied in this experimental set up. The feed phase solutions containing PNP and deionized water were prepared with the desired concentrations. Also, in the all experiments, deionized water was used as acceptor phase. The organic membrane phase was made up by organic solvents. At the beginning of the experiments, an equal volume of each phase was taken and the feed, and stripping phases were poured into the inner chamber and between the two walls, respectively, then the membrane phase was slowly poured onto these two phases. The acceptor and the donor phases were stirred magnetically, and the membrane phase was stirred by a mechanical stirrer. The $\mathrm{pH}$ of the donor phase was adjusted to the desired value with $0.05 \mathrm{M} \mathrm{H}_{2} \mathrm{SO}_{4}$. The duration of each kinetic run was 5 hours. Upon completion of this time, sampling from each phase was slowly carried out with a large syringe, and the PNP concentration was analyzed by spectrophotometry (CARY BIO 50 spectrophotometer).

Each experiment was carried out in duplicate and the average results are presented.

The removal efficiency $(E)$ was determined according to Eq. (1):

$$
E=\left[\frac{\left(C_{f 0}-C_{f}\right)}{C_{f 0}}\right] 100
$$

where $E$ is the removal efficiency, $C_{f 0}$ is the initial concentration of PNP in feed phase, $C_{f}$ is the concentration of PNP after extraction in feed phase, respectively. 


\section{Results and discussion}

\section{Influence of solvent type on extraction of PNP}

Xylene, toluene, benzene, n-hexane, olive oil, canola oil, and corn oil were used in order to investigate the influence of organic solvent on the extraction of PNP from aqueous solution using the BLM. The experimental results are presented in Table 1.

There is a relationship between solvent characteristics and transport efficiency. It seems that transport efficiency is a function of solvent dielectric constant ${ }^{19}$. Specifically, the salvation capability of ions and complexes increase with increasing solvent dielectric constant ${ }^{20}$. The dielectric constant of studied solvents is shown in Table 2.

As shown in Table 1, almost all solvents are effective in transportation of PNP to membrane phase because their dielectric constant is close to each other (Table 2). But in the next step, for transportation of PNP from membrane phase to acceptor phase, the most effective solvents are xylene, toluene and benzene because of their viscosity. The various edible oils are capable of separating the PNP from feed phase, but they are more viscous than other solvents, which is why they are problematic in transportation of the PNP into the aqueous acceptor phase. In other words, the transportation of PNP into the acceptor phase is a function of the diffusion

Table 1 -Partitioning of PNP through BLM with different solvents

\begin{tabular}{cccccc}
\hline Solvents & $\begin{array}{c}\text { Acceptor } \\
\left(\mathrm{mg} \mathrm{L}^{-1}\right)\end{array}$ & $\begin{array}{c}\text { Membrane } \\
\left(\mathrm{mg} \mathrm{L}^{-1}\right)\end{array}$ & $\begin{array}{c}\text { Feed } \\
\left(\mathrm{mg} \mathrm{L}^{-1}\right)\end{array}$ & $\begin{array}{c}\text { Removal } \\
\text { efficiency (\%) }\end{array}$ \\
\hline n-Hexane & 12 & 38 & 100 & $8 \pm 0.3$ \\
Toluene & 48 & 43 & 59 & $32 \pm 1.6$ \\
Xylene & 57 & 62 & 31 & $38 \pm 0.6$ \\
Benzene & 45 & 79 & 26 & $30 \pm 0.5$ \\
Corn oil & 10 & 110 & 30 & $7 \pm 0.2$ \\
Canola oil & 10 & 91 & 49 & $7 \pm 0.2$ \\
Olive oil & 11 & 51 & 88 & $7 \pm 0.2$ \\
\hline
\end{tabular}

Table 2 - Dielectric constant of different solvents

\begin{tabular}{c|c}
\hline Solvent & Dielectric constant \\
\hline Benzene & 2.27 \\
Toluene & 2.40 \\
Xylene & 2.57 \\
n-Hexane & 2.00 \\
Edible oil & $3.0-4.0$ \\
\hline
\end{tabular}

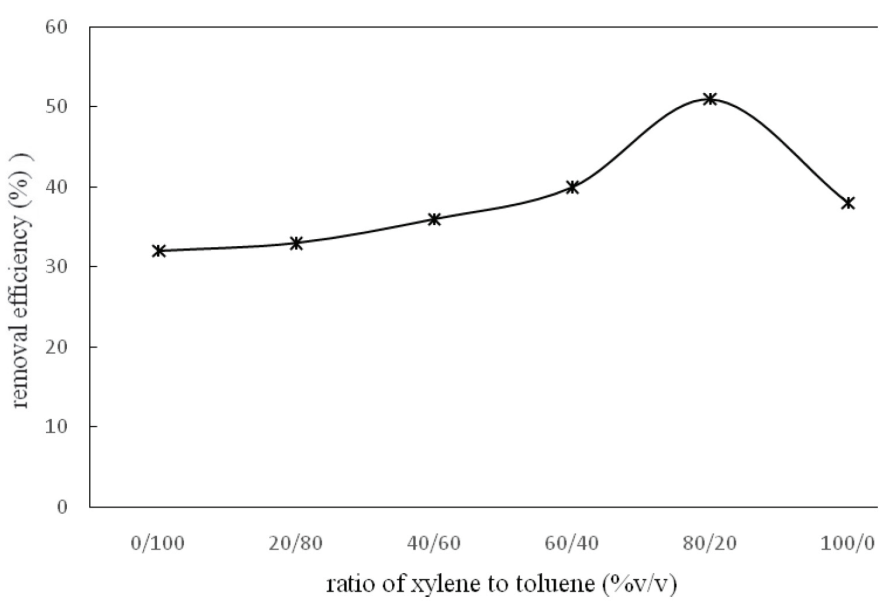

Fig. 2 -Different volume ratios of xylene and toluene on PNP transport through the BLM

coefficient that is inversely related to solvent vis$\operatorname{cosity}^{20}$. In addition, structural similarity of xylene, toluene and benzene is effective in the transfer of PNP to acceptor phase ${ }^{17,19}$. Therefore, the organic solvent selection is an effective parameter in the efficiency of separation.

Among all the studied solvents, the highest removal efficiency of PNP was observed for xylene and toluene, therefore these solvents were selected for further study.

\section{Influence of different volume ratios of xylene and toluene on PNP transport through the BLM}

Literature survey reveals that much work has been carried out on the use of mixed solvents as membrane phase in transport of target molecule, using bulk liquid membrane ${ }^{18-19,21}$.

An optimum in transport efficiency of PNP from aqueous solution was observed by altering the volume ratio of xylene to toluene to $80: 20(\% \mathrm{v} / \mathrm{v})$, while a very high or low xylene/toluene ratio resulted in relatively lower yields (Fig. 2).

However, the removal yield of PNP at the xylene/toluene ratio of 80:20 was not statistically different from that of the xylene/toluene ratio of 60:40 and 100:0 (Fig. 2). This result showed that the xylene/toluene ratio tolerable limit for the removal of PNP was not too narrow. This suggests that, among other chemical and physical factors, the xylene/toluene ratio is another important factor that needs to be optimized in the removal of PNP from aqueous solution. Based on the obtained results in literature and the present work, the choice of mixed solvent seemed to be an important parameter to be controlled in the transport of solute by BLM technique. Therefore, this ratio was chosen in the subsequent experiments. 


\section{Influence of different salts on transport of PNP through the BLM}

Salts are frequently used in extraction processes to improve partitioning of the target molecules between the phases ${ }^{22}$. Thus, the selection of the salt employed in the extraction system is one of the key points of this technique. To ensure the efficiency of extraction, the effect of different salts $\left(\mathrm{NH}_{4} \mathrm{NO}_{3}\right.$, $\mathrm{NH}_{4} \mathrm{Cl}, \mathrm{NaCl}, \mathrm{Na}_{2} \mathrm{SO}_{4},\left(\mathrm{NH}_{4}\right)_{2} \mathrm{SO}_{4}$, and $\left.\mathrm{KCl}\right)$ on the transportation of PNP was studied in a stirred liquid membrane system. The results are summarized in Table 3. It can be found that the partitioning of PNP was strongly dependent on the type of salt. As regards the salt effect, $\mathrm{Na}_{2} \mathrm{SO}_{4}$ exhibits higher removal efficiency. From Table 3, it can be concluded that sulfate salts show higher PNP removal efficiency when compared to chloride and nitrate salts. This is mainly due to the higher salting-out effect by the sulfate salts. The salting-out ability of a cation or anion is related to its ionic charge and hydration radius. The strength of ion solvation mainly depends on electrostatic attraction ${ }^{23}$. The salting-out ability can also be related to the Gibbs free energy of hydration of ions $\left(\Delta G_{\mathrm{hyd}}\right)$, as proposed by Marcus ${ }^{24}$. It was found that better salting-out is observed when the ions have a more negative Gibbs free energy. The Gibbs free energies of hydration for sulfate, chloride, and nitrate ions are $-1080,-340$ and -300 $\mathrm{kJ} \mathrm{mol}^{-1}$, respectively, which also certify the conclusion that the salting-out ability of sulfate salts is stronger than that of chloride and nitrate salts. The more negative is the $\Delta G$ hyd value of an ion, the greater is the salting out ability. Furthermore, anions with a higher valence are better salting-out agents than anions with a lower-valence, because higher-valence anions are hydrated by more water than lower-valence anions (anion sulfate has a higher-valence than anions of chloride and nitrate; 2, 1 , and 1 , respectively). Furthermore, among sulfate salts, this behavior can be explained by comparing the $\Delta G$ hyd values for the cations sodium and ammonium (-365 and $-285 \mathrm{~kJ} \mathrm{~mol}^{-1}$ respectively), it can be concluded that the salting-out ability of $\mathrm{Na}_{2} \mathrm{SO}_{4}$ is

Table 3-Influence of different salts on transport of PNP through $80 \%$ xylene-20\% toluene liquid membrane

\begin{tabular}{c|c}
\hline Salt type & Removal efficiency (\%) \\
\hline $\mathrm{NaCl}$ & $50 \pm 1.1$ \\
$\mathrm{NH}_{4} \mathrm{Cl}$ & $49 \pm 1.6$ \\
$\mathrm{KCl}$ & $51 \pm 0.8$ \\
$\mathrm{NH}_{4} \mathrm{NO}_{3}$ & $33 \pm 1.1$ \\
$\mathrm{Na}_{2} \mathrm{SO}_{4}$ & $63 \pm 1.0$ \\
$\left(\mathrm{NH}_{4}\right)_{2} \mathrm{SO}_{4}$ & $54 \pm 0.9$ \\
\hline
\end{tabular}

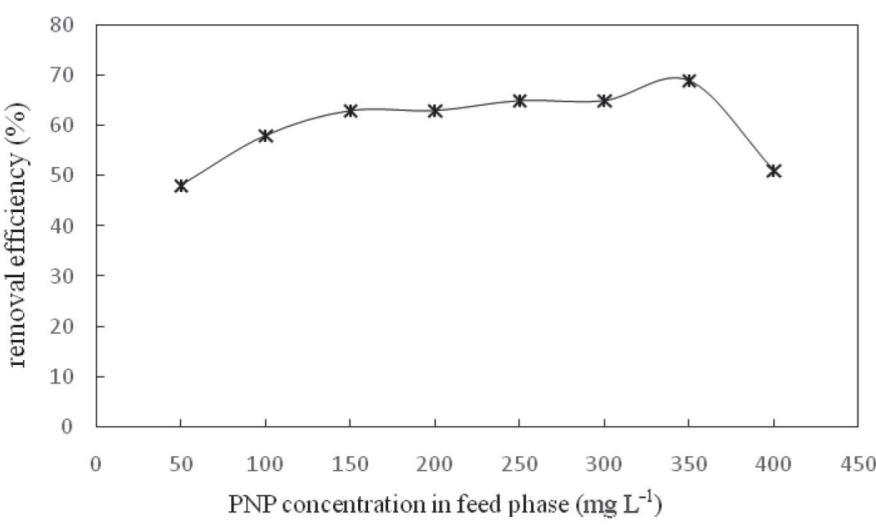

Fig. 3 - Effect of different PNP concentrations on transport of PNP through BLM

stronger than $\left(\mathrm{NH}_{4}\right)_{2} \mathrm{SO}_{4}$ (the two salts have the same anion). Thus, the type of salt used was critical for the PNP recovery and partitioning in the stirred liquid membrane system. Therefore, with regard to this result, $\mathrm{Na}_{2} \mathrm{SO}_{4}$ was chosen as the salt in feed phase in the subsequent experiments.

\section{Influence of PNP concentration in aqueous feed phase on transport efficiency}

In order to study the effect of initial concentration of PNP in the aqueous feed phase on the PNP removal efficiency, experiments were performed with different initial concentrations of PNP (50-400 $\mathrm{mg} \mathrm{L}^{-1}$ ). The removal efficiency of PNP gradually increased from $48 \%$ to $66 \%$ in the concentration of 50-300 mg L-1, respectively, and reached a maximum of $69 \%$ at concentration $350 \mathrm{mg} \mathrm{L}^{-1}$. However, at a concentration of $400 \mathrm{mg} \mathrm{L}^{-1}$, the PNP removal efficiency extremely reduced to $51 \%$ (Fig. 3). This result is in agreement with some works presented in the literature that affirm that PNP concentration had an effect on removal efficiency of PNP in the aqueous feed phase ${ }^{17,19}$. In general, the driving force for mass transfer is typically the difference in chemical potential, and chemical potential is directly related to concentration gradient. The commodity flow rate through phases is proportional to its concentration gradient. Thus, the increase in PNP concentration in feed phase causes the increase in flux of transportation. Moreover, the pertraction is controlled by diffusion and extraction process at the interface between feed phase and membrane phase $^{17}$. Due to limitations in the design of liquid membrane system and reduction of the interface between phases, PNP transportation through the interface is limited. Therefore, the increase in PNP concentration more than a specific amount in feed phase causes the saturation of interface between feed and membrane phases and accumulation of PNP molecules on interface, and consequently reduction in PNP transportation. 


\section{Influence of $\mathrm{pH}$ of the feed phase on transport of PNP through the BLM}

The $\mathrm{pH}$ of the system influences the ionizable groups of a target molecule and alters its surface charges. At $\mathrm{pH}=7.15$, the concentration of neutral molecules and their anions are equal ([PNP-OH ]= $\left.\left[\mathrm{PNP}^{-} \mathrm{O}^{-}\right]\right)$, and the increase in $\mathrm{pH}$ leads to negativation of molecule charge ([PNP-OH $]<\left[\mathrm{PNP}^{-}{ }^{-}\right]$). Therefore, $\mathrm{pH}$ of the system is a key factor that influences the partitioning of PNP due to its change in $\mathrm{pH}$. In order to know the influence of the feed phase $\mathrm{pH}$ on transport of PNP through the liquid membrane, experiments were performed at different $\mathrm{pH}$ values (2-8), and the results are shown in Fig. 4. The obtained results prove that the transport efficiency of PNP in the receiving phase depends extremely on the $\mathrm{pH}$. It was observed that with an increase in $\mathrm{pH}$ to alkaline conditions $(\mathrm{pH}=8)$, the $\mathrm{PNP}$ partitioned to the feed phase and hence the transport efficiency extremely decreased from $68 \%$ to $30 \%$. The change in efficiency of the PNP separation can be explained by considering the change in the charge of the PNP surface. As the $\mathrm{pH}$ of the system increased above $\mathrm{pH}=7.15$, the PNP surface charge become negative. As a result, transportation of the PNP into the membrane phase decreased. Thus, the transport efficiency of PNP of less than $30 \%$ at $\mathrm{pH}=8$ was observed. Diaconu et al. ${ }^{25}$ have also observed similar effects for PNP transport through membrane phase-chloroform.

In addition, these results can be correlated with the following three equilibria that take place at the interfaces of the membrane system ${ }^{25}$. The equilibrium between the PNP and an acid character in the acceptor phase is as follows:

$$
(\mathrm{Ar}-\mathrm{OH})_{\mathrm{F}}+(\mathrm{HOH})_{\mathrm{F}} \rightleftharpoons\left(\mathrm{Ar}-\mathrm{O}^{-}\right)_{\mathrm{F}}+\left(\mathrm{H}_{3} \mathrm{O}^{+}\right)_{\mathrm{F}}(2)
$$

This equilibrium is controlled by the $\mathrm{pH}$. In acidic $\mathrm{pH}$, due to the presence of ions $\mathrm{H}^{+}$, the undissociated form of the PNP predominates. On the other hand, the solubility of PNP in the membrane phase increases in undissociated form. But in alkaline feed phase, because PNP is an acidic substance, it converts to the ionic form, and as a result, the solubility of PNP in membrane phase decreases, and therefore more PNP remains in feed phase.

This is distributed between the feed phase and the membrane according to the following partition equilibrium:

$$
(\mathrm{Ar}-\mathrm{OH})_{\mathrm{F}} \rightleftharpoons(\mathrm{Ar}-\mathrm{OH})_{\mathrm{M}}
$$

After the molecules of the PNP go through the membrane, the next partition equilibrium takes place at the interface between the membrane and the receiving phase:

$$
(\mathrm{Ar}-\mathrm{OH})_{\mathrm{M}}+\left(\mathrm{HO}^{-}\right)_{\mathrm{A}} \rightleftharpoons\left(\mathrm{Ar}-\mathrm{O}^{-}\right)_{\mathrm{A}}+(\mathrm{HOH})_{\mathrm{A}}
$$

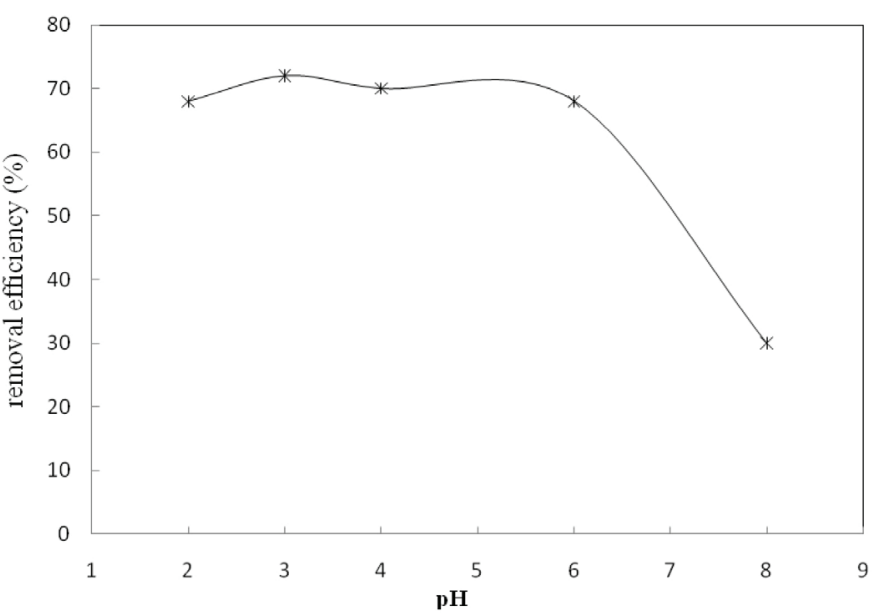

Fig. 4 - Effect of feed phase $p H$ on transport of PNP through $B L M$

This mechanism is validated in Fig. 4 with the increase in transport efficiency by decreasing the $\mathrm{pH}$ of the feed phase in this BLM system.

\section{Mathematical model}

The mathematical model was mostly used to explain pertraction in bulk liquid membrane systems. This model presumes that the transport of a solute can obey this kinetic scheme $e^{1,17}$ :

$$
C_{\mathrm{f}} \stackrel{K_{1}}{\longrightarrow} C_{\mathrm{LM}} \stackrel{K_{2}}{\longrightarrow} C_{\mathrm{s}}
$$

where $C$ is the concentration of the solute in the feed or donor phase (f), liquid membrane (LM), and stripping or acceptor (s) phase, $K_{1}$ and $K_{2}$ are the pseudo-first-order apparent membrane input and output rate constants. In general, to simplify the model equations, the reduced PNP concentrations are used. Consequently, time dependence of the reduced PNP concentrations in the donor, membrane, and acceptor phases (non-steady-state kinetic regime) is:

$$
\begin{gathered}
R_{\mathrm{f}}=e^{-k_{1} t} \\
R_{\mathrm{LM}}=\frac{k_{1}}{k_{2}-k_{1}}\left(e^{-k_{1} t}-e^{-k_{2} t}\right) \\
R_{\mathrm{s}}=1+\frac{1}{k_{1}-k_{2}}\left(k_{2} e^{-k_{1} t}-k_{1} e^{-k_{2} t}\right)
\end{gathered}
$$

where: $R_{\mathrm{f}}, R_{\mathrm{LM}}$ and $R_{\mathrm{s}}$ are reduced mole fractions of the PNP in the feed (f), liquid membrane (LM), and stripping phase (s), respectively. It is obvious that $R_{\mathrm{f}}$ decreases mono-exponentially with time; the time variation of $R_{\mathrm{s}}$ represents a monotonically increasing sigmoid type curve, while the time variation of $R_{\mathrm{LM}}$ represents the maximum ${ }^{18}$. 
Maximum reduced PNP concentration of membrane phase can be calculated from the equation:

$$
R_{M}^{m x}=\left(\frac{K_{1}}{K_{2}}\right)^{\frac{K_{2}}{K_{1}-K_{2}}}
$$

while its position along the time axis is specified by the equation:

$$
t_{\text {max }}=\frac{\ln \left(\frac{K_{1}}{K_{2}}\right)}{K_{1}-K_{2}}
$$

The pseudo-first-order apparent membrane input and output rate constants can be used at the determination of the maximum flux $\left(J_{\max }\right)$ :

$$
\begin{aligned}
& J_{\text {max }}=-K_{1}\left(\frac{K_{1}}{K_{2}}\right)^{\frac{K_{1}}{K_{1}-K_{2}}}= \\
& =K_{2}=\left(\frac{K_{1}}{K_{2}}\right)^{\frac{K_{2}}{K_{1}-K_{2}}}=-J_{F P \max }=J_{S P \max }
\end{aligned}
$$

where: $J_{F P \max }=$ membrane input flux; $J_{S P \max }=$ membrane output flux.

After calculation of the reduced PNP concentration in different phases, the model parameters $k_{1}$ and $k_{2}$ were obtained by fitting Eqs. (6-8) to the experimental data. The experimental data confirmed a good accordance with the model. This is illustrated in Fig. 5. Solid lines in Fig. 5 denote the values calculated by adjusting the model (Eqs. 6-8) to the experimental data. The model curves of time dependence of PNP concentration in the feed, liquid

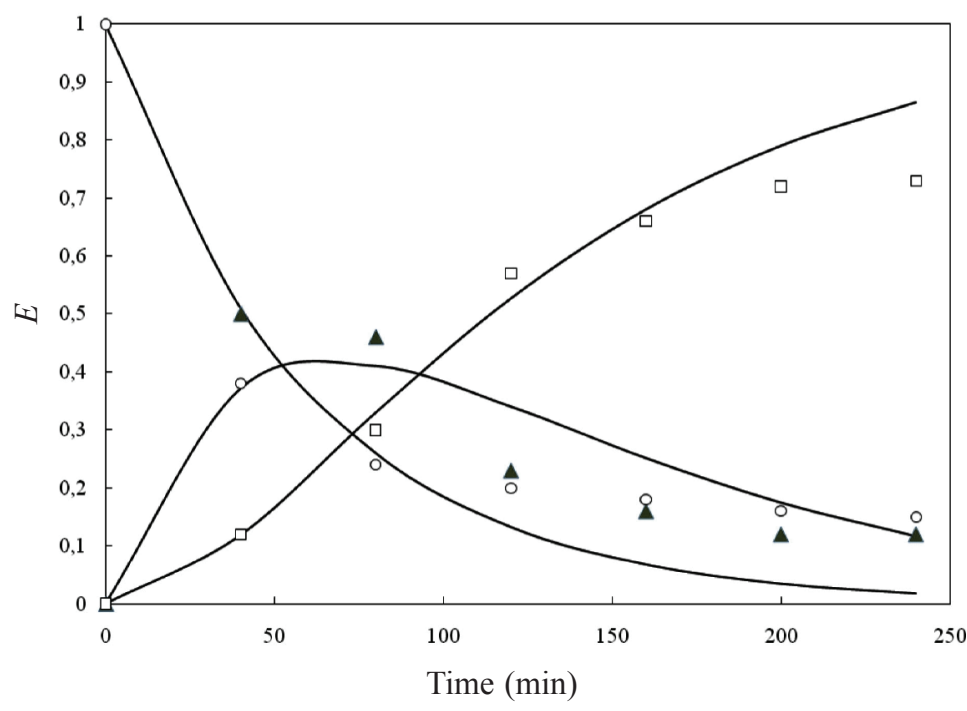

\begin{tabular}{|c|c|}
\hline$k_{1}\left(\mathrm{~s}^{-1}\right)$ & $2.80 \cdot 10^{-4}$ \\
\hline$k_{2}\left(\mathrm{~s}^{-1}\right)$ & $2.16 \cdot 10^{-4}$ \\
\hline$R_{L M}^{\max }$ & 2.40 \\
\hline$t_{\max }(\mathrm{s})$ & 4054.8 \\
\hline$J_{\max }\left(\mathrm{mol} \mathrm{cm} \mathrm{cm}^{-2} \mathrm{~s}^{-1}\right)$ & $5.2 \cdot 10^{-4}$ \\
\hline$\sigma^{2}$ & 0.92 \\
\hline$s d$ & 0.08 \\
\hline
\end{tabular}

Fig. 5 - Experimental results for PNP pertraction in the bulk liquid membrane: $\circ$ feed phase; $\square$ stripping phase; $\Delta$ liquid membrane and solid lines - values calculated using the model membrane and stripping solution are in accordance with the experimental data (Fig. 5). However, some discrepancies between the calculated and experimental data for longer periods of pertraction were observed. For all the investigated dependences $(c=f(t))$, the values of determination coefficient $\left(R^{2}\right)$ were higher than 0.92 . The values of the model parameters are presented in Table 4.

In addition, the fitting parameters, correlation coefficients $\left(\sigma^{2}\right)$, and standard deviations $(s d)$ are listed in Table 4. According to the obtained determination coefficient and standard deviations, it can be concluded that, Eqs. (6-8) can successfully correlate the pertraction of PNP in the investigated systems.

As shown in Table 4, $t_{\max }$ is less than 1.5 hours, while the mixing time taken for the tests was 5 hours, so it can be concluded that the time given to the system was sufficient.

\section{Conclusions}

In the present paper the possibility of extraction and pertraction of $p$-nitrophenol from aqueous solution using bulk liquid membrane were examined. The results showed that the most effective solvents for separation of PNP were xylene, toluene, benzene because of their structural similarity. Among the investigated organic solvent types, the mixture of $80 \%$ xylene $-20 \%$ toluene liquid membrane resulted in the highest removal efficiency. Also, $\mathrm{Na}_{2} \mathrm{SO}_{4}$ salt had the most effect on the transportation of PNP because of its stronger salting-out effect. The effect of the feed phase $\mathrm{pH}$ on PNP transport showed that the highest removal efficiency of PNP was obtained at acidic $\mathrm{pH}$. Furthermore, the experimental data of the studied system were satisfactorily fitted by a kinetic model of two consecutive irreversible first order reactions. According to the obtained results, it can be concluded that, this model can successfully correlate the PNP pertraction. 


\section{Nomenclature}

$$
\begin{aligned}
& \text { A } \quad-\text { membrane area, } \mathrm{cm}^{2} \\
& \text { C - concentration, mol L } \mathrm{L}^{-1} \\
& C_{f, 0} \quad-\text { initial concentration of the feed phase, } \mathrm{mol} \mathrm{L}^{-1} \\
& C_{f} \quad-\text { the concentration of PNP after extraction in } \\
& \text { feed phase, } \mathrm{mol} \mathrm{L}^{-1} \\
& R \quad \text { - reduced mole fraction of the solute } \\
& K_{1} \quad \text { - pseudo-first-order apparent membrane } \\
& \text { entrance rate constant, } \mathrm{s}^{-1} \\
& K_{2} \quad-\text { pseudo-first-order apparent membrane exit } \\
& \text { rate constant, } \mathrm{s}^{-1} \\
& J_{\max } \quad-\text { maximum flux in the stripping phase, } \\
& \mathrm{mol} \mathrm{cm} \mathrm{cm}^{-2} \mathrm{~s}^{-1} \\
& R_{L M}^{\max } \text { - the maximum of the reduced concentration in } \\
& \text { the LM } \\
& t \quad-\text { time, } \mathrm{s} \\
& t_{\max } \quad-\text { the time at which the } R_{L M}^{\max } \text { maximum is } \\
& \text { observed, s } \\
& \sigma^{2} \quad-\text { correlation coefficients } \\
& \text { sd - standard deviations } \\
& \text { E - removal efficiency }
\end{aligned}
$$

\section{Subscripts}

f, s, LM - feed, stripping, liquid membrane phase, respectively

\section{References}

1. Diaconu, I., Mirea, C. M., Ruse, E., Nechifor, G., Selective recovery of phenolic derivatives through the technique of liquid membranes, Environ. Eng. Manag. J. 14(3) (2015) 625.

2. Lin, K. Y. A., Hsieh, Y. T., Copper-based metal organic framework (MOF), HKUST-1, as an efficient adsorbent to remove $p$-nitrophenol from water, J. Taiwan Inst. Chem. Eng. 50 (2015) 223. doi: https://doi.org/10.1016/j.jtice.2014.12.008

3. Moussout, H., Slimane, S. S., Chraibi, S., Echetna, M., Ahlafi, H., Study of the paranitrophenol adsorption on the commercial bentonite, J. Environ. Earth Sci. 4(6) (2014) 27.

4. Sun, Y., Zhou, J., Cai, W., Zhao, R., Yuan, J., Hierarchically porous NiAl-LDH nanoparticles as highly efficient adsorbent for $p$-nitrophenol from water, Appl. Surf. Sci. 349 (2015) 897. doi: https://doi.org/10.1016/j.apsusc.2015.05.041

5. Yu, P., Chang, Z., Ma, Y., Wang, S., Cao, H., Hua, C., Liu, $H$., Separation of $p$-nitrophenol and $o$-nitrophenol with three-liquid-phase extraction system, Sep. Purif. Technol. 70(2) (2009) 199. doi: https://doi.org/10.1016/j.seppur.2009.09.016

6. Spain, J. C., Gibson, D. T., Pathway for biodegradation of $p$-nitrophenol in a Moraxella sp., Appl. Environ. Microbiol. 57(3) (1991) 812.
7. Lima, S. A. C., Castro, P. M. L., Morais, R., Biodegradation of $p$-nitrophenol by microalgae, J. Appl. Phycol. 15(2-3) (2003) 137

8. Liou, R. M., Chen, S. H., Huang, C. H., Lai, C. L., Shih, C. Y., Chang, J. S., Hung, M. Y., Catalytic wet peroxide oxidation of $p$-nitrophenol by $\mathrm{Fe}$ (III) supported on resin, Water Sci. Technol. 62(8) (2010) 1879. doi: https://doi.org/10.2166/wst.2010.370

9. Zaggout, F. R., Ghalwa, N. A., Removal of o-nitrophenol from water by electrochemical degradation using a lead oxide/titanium modified electrode, J. Environ. Manage. 86 (2008) 291. doi: https://doi.org/10.1016/j.jenvman.2006.12.033

10. Mnif, A., Tabassi, D., Ben Sik Ali, M., Hamrouni, B., Phenol removal from water by AG reverse osmosis membrane, Environ. Prog. Sustain. Energy. 34 (2015) 982. doi: https://doi.org/10.1002/ep.12078

11. Essam, T., Aly Amin, M., El Tayeb, O., Mattiasson, B., Guieysse, B., Solar-based detoxification of phenol and $p$-nitrophenol by sequential $\mathrm{TiO}_{2}$ photocatalysis and photosynthetically aerated biological treatment, Water Res. 41(8) (2007) 1697. doi: https://doi.org/10.1016/j.watres.2007.01.015

12. Mishra, K. P., Gogate, P. R., Intensification of sonophotocatalytic degradation of $p$-nitrophenol at pilot scale capacity, Ultrason Sonochem. 18(3) (2011) 739. doi: https://doi.org/10.1016/j.ultsonch.2010.11.004

13. Wojciech Cichy, W., Schlosser, S., Szymanowski, J., Extraction and pertraction of phenol through bulk liquid membranes, J. Chem. Technol. Biotechnol. 80 (2005) 189. doi: https://doi.org/10.1002/jctb.1178

14. Ng, Y. S., Jayakumar, N. S., Hashim, M. A., Performance evaluation of organic emulsion liquid membrane on phenol removal, J. Hazard. Mater. 184 (2010) 255. doi: https://doi.org/10.1016/j.jhazmat.2010.08.030

15. An, H., Li, X., Yang, Q., Wang, D., Xie, T., Zhao, J., Xu, Q., Chen, F., Zhong, Y., Yuan, Y., Zeng, G., The behavior of melamine in biological wastewater treatment system, J. Hazard. Mater. 322(Pt B) (2017) 445.

16. Reddy, T. R., Ramkumar, J., Chandramouleeswaran, S., Reddy, A. V. R., Selective transport of copper across a bulk liquid membrane using 8-hydroxy quinoline as carrier, J. Membr. Sci. 351 (2010) 11. doi: https://doi.org/10.1016/j.memsci.2010.01.021

17. Szczepański, P., Diaconu, I., Transport of p-nitrophenol through an agitated bulk liquid membrane, Sep. Sci. Technol. 47 (2012) 1725. doi: https://doi.org/10.1080/01496395.2012.659316

18. Irdemez, S., Topcu, N., Ylldız, Y. S., Demircioglu, N., Effect of organic solvent type on the removal of nitrate ion using liquid membrane technique, Stoch. Environ. Res. Risk Assess 21 (2006) 175. doi: https://doi.org/10.1007/s00477-006-0054-5

19. Kislik, V. S., Liquid membranes-Principles \& Applications in Chemical Separations \& wastewater. first ed. Amsterdam, The Netherlands Linacre House, Jordan Hill: Oxford (2010).

20. Izatt R. M., Jr, D. W. M., Brown, P. R., Lambf, J. D., Christensen, J. J., The influence of halocarbon solvent on macrocycle-mediated cation transport through liquid membranes, J. Membr. Sci. 28(1) (1986) 69. doi: https://doi.org/10.1016/S0376-7388(00)82200-0

21. Dernln, S., Palmas, S., Polcaro, A. M., Marongiu, B., Extraction and transport of $\mathrm{Na}^{+}$and $\mathrm{K}^{+}$in a liquid membrane containing crown ethers: Effect of the mixed solvent, J. Chem. Eng. Data 37 (1992) 281. doi: https://doi.org/10.1021/je00006a039 
22. Khayati, G., Talesh, S. A., Yazdanshenas, M., Partitioning of propionic acid in polyethylene glycol/different salts of sulfate aqueous two-phase systems, Sep. Sci. Technol. 49 (2014) 2741.

doi: https://doi.org/10.1080/01496395.2014.941490

23. Khayati, G., Shariari, M., Measurement and correlation of phase diagram data of hydrophilic alcohols (1-propanol/ 2 -propanol $)+$ salts $\left(\mathrm{Na}_{2} \mathrm{SO}_{4} /\left(\mathrm{NH}_{4}\right)_{2} \mathrm{SO}_{4} / \mathrm{NH}_{4} \mathrm{NO}_{3}\right)+$ water systems, Chem. Biochem. Eng. Q. 30(1) (2016) 73.

doi: https://doi.org/10.15255/CABEQ.2015.2308
24. Marcus, Y., Thermodynamics of solvation of ions. Part 5.-Gibbs free energy of hydration at 298.15 K, J. Chem. Soc., Faraday Trans. 87 (1991) 2995.

doi: https://doi.org/10.1039/FT9918702995

25. Diaconu, I., Nechifor, N., Nechifor, A. C., Totu, E. E., Ruse, E., The transport of nitrophenols through liquid membranes, Rev. Chim. (Bucureti) 60 (2009) 1243. 